\title{
Time of delirium onset and prognosis amongst Southern Brazilian hospitalized elderly patients
}

\author{
André Luiz Moschetta ${ }^{1}$, Carine Volkweis Silveira ${ }^{1}$, Roberta Rigo Dalacorte', \\ Rodolfo Herberto Schneider ${ }^{2}$, Irênio Gomes da Silva Filho
}

\begin{abstract}
The prognostic significance of delirium in hospitalized elderly has not yet been fully clarified. Objectives: The present study was designed to evaluate the relationship between prevalent delirium (PrD), incident delirium ( $\mathrm{InD}$ ) and final outcome. Methods: A historical cohort of 261 patients was selected. delirium was diagnosed using the Confusion Assessment Method. Results: The total frequency of delirium detected was $42.5 \%$ $31.4 \% \mathrm{PrD}$ and $16.2 \% \mathrm{InD}$. Among patients with $\mathrm{InD}$, the average length of hospital stay was 9.1 days longer than for patients without delirium ( $\mathrm{p}=0.002$ ), and the hospital mortality associated with $\mathrm{InD}$ was $48 \%$ versus $2.7 \%$ for those without delirium $(\mathrm{p}<0.001)$. However, no difference was observed between patients with PrD and those without delirium. Conclusions: These results suggest that, when investigating delirium and prognosis amongst hospitalized elderly, it is fundamental to differentiate in terms of time of onset. Furthermore, the absence of delirium seems to be an important protective factor.
\end{abstract}

Key words: delirium, acute confusional state, elderly, prognostic, hospitalization.

\begin{abstract}
Momento de início do delirium e prognóstico em pacientes idosos hospitalizados no sul do Brasil Resumo - O significado do prognóstico de delirium em idosos hospitalizados ainda não está completamente elucidado. Objetivos: O presente estudo foi designado para avaliar a relação entre delirium prevalente (DeP), delirium incidente (DeI) e o desfecho final. Métodos: Uma coorte histórica de 261 pacientes foi selecionada. delirium foi diagnosticado pelo Confusion Assessment Method. Resultados: A freqüência total de delirium foi de 42.5\%, DeP 31.4\%, e DeI 16.2\%. Para pacientes com DeI, a média de duração de hospitalização foi 9.1 dias maior do que aqueles sem delirium ( $\mathrm{p}=0.002$ ), e a mortalidade hospitalar associada a DeI foi de $48.3 \%$ contra $2.7 \%$ dos livres de delirium $(\mathrm{p}<0.001)$. Contudo, não houve diferença entre pacientes com DeP e sem delirium. Conclusões: Os resultados sugerem que, ao estudar delirium e prognóstico entre idosos hospitalizados, é fundamental diferenciar o problema quanto ao seu momento de início. Além disso, não apresentar delirium parece constituir-se num fator protetor importante.
\end{abstract}

Palavras-chave: delirium, estado confusional agudo, idoso, prognóstico, hospitalização.

Individuals aged 60 years or older make up approximately $12 \%$ of the population in the southern region of Brazil ${ }^{1}$ and represent about $20 \%$ of all patients admitted to the regions' general hospitals. ${ }^{2-4}$ This patient group uses the hospital services more intensively than those of other age groups because their treatment and recuperation takes longer and costs more. ${ }^{4}$ delirium, or acute confusional state, is an organic mental syndrome which is acute, transient and fluctuating, that occurs frequently in hospitalized elderly people, ${ }^{5,6}$ and is considered the most common hospital complication in this population. ${ }^{7-9}$

Irrespective of the reason for hospitalization, it is estimated that 15 to $20 \%$ of the elderly will be in an acute confusional state on admission, and 25 to $55 \%$ will develop the condition during their hospital stay. ${ }^{7,10}$ This frequency depends on the characteristics of the patient and their diseases, on the care dispensed and the sensitivity of the method used for diagnosis. ${ }^{11}$ The link between delirium

${ }^{1} \mathrm{MD}$, Institute of Geriatrics and Gerontology, Pontifical Catholic University, Porto Alegre RS, Brazil. ${ }^{2} \mathrm{MD}$, PhD, Institute of Geriatrics and Gerontology, Pontifical Catholic University, Porto Alegre RS, Brazil.

André L.Moschetta - Instituto de Geriatria e Gerontologia - Av. Ipiranga 6690 / $3^{\circ}$ andar - 90610-000 Porto Alegre RS - Brazil. E-mail: andremoschetta@gmail.com Disclosure: The authors report no conflicts of interest.

Received September 29, 2009. Accepted in final form November 16, 2009. 
and severity of acute morbid states is well known. ${ }^{12}$ Studies on patients hospitalized in intensive care units, or those suffering from terminal diseases, have demonstrated incidences of the syndrome up to $80 \% .^{10,12,13}$

The biological mechanisms involved in the genesis of delirium are not yet fully understood. It is known that a complex relationship exists between individual vulnerability and aggressor factors, often multiple, making it more difficult to determine the exact role delirium plays in the disease process. Consequently, the data in the literature on the prognostic implications of delirium remain controversial. Although various investigative studies, apparently well conducted, have demonstrated an association between this acute confusional state and hospital mortality, ${ }^{11,14}$ prolonged hospital stay, ${ }^{15,16}$ functional decline and greater rates of discharge to places other than the home, ${ }^{6,7,17,18}$ other studies of the same quality have found no such association. ${ }^{19-23}$ It is possible that one of the principal reasons for this difference in results is the failure to distinguish between prevalent $d e$ lirium (PrD) and incident delirium ( $\mathrm{InD}$ ) where this likely leads to the different prognostics. ${ }^{24,25}$ In fact, none of the studies cited above evaluated the differences between the types of delirium with respect to the time of onset.

An intensive bibliographic search of the MEDLINE and SCIELO databases, and the respective reference textbooks identified only one paper in which the prognosis of the two presentations of delirium were studied separately. In a study of a cohort of 359 patients, McCusker et al. compared the duration of hospital stay amongst elderly patients with $\operatorname{PrD}$ versus those with $\mathrm{InD}$, and those without either delirium. They found an association of the duration of hospital stay and delirium only in the group of patients with InD. ${ }^{24}$ This finding reinforces the hypothesis that $\operatorname{PrD}$ and InD contribute differently to prognosis.

The present study was conducted in view of the lack of consensus over the effect on prognosis of delirium in elderly patients, the scarcity of data differentiating the time of onset, and the scant information available on its occurrence in our population. The objective was to describe and compare the duration of hospital stay and mortality in elderly patients with $\operatorname{PrD}$ versus those with $\mathrm{InD}$, and without either delirium, who had been hospitalized in the geriatric ward of a general hospital in the south of Brazil.

\section{Methods}

The study was conducted in a geriatric ward with 16 beds -8 for use by the Brazilian public health system (Sistema Unico de Saúde - SUS ) and 8 for private patients - in a university general hospital in the south of Brazil. A historical cohort was constructed based on the hospital patient records of all those aged 60 years or older who had been hospitalized consecutively during 2007. We excluded all individuals who had stayed more than 24 hours in another hospital sector $(n=102)$, those that had been discharged for transfer or non-medical reasons $(\mathrm{n}=3)$, and those that had been discharged after less that 24 hours of hospitalization $(\mathrm{n}=2)$.

These patient files are completed by the medical team of the Geriatric Service, all of whom receive frequent training in how to detect delirium. The diagnoses were reached using the Confusion Assessment Method (CAM) which is accurate, precise and valid for this purpose. ${ }^{26,27}$ The criteria used for definition of the cases were: a report of "delirium", "acute confusional state" or "acute confusional state with organic origin", or the presence of other information meeting the CAM criteria. Prevalent delirium was defined by a diagnosis of delirium in the first 24 hours of admission, and $\mathrm{InD}$ when delirium was detected after this period. Data was also collected on the demographic details (sex, age and health plan), the cause and characteristics of hospitalization (acute or elective; duration of hospital stay) and on the basic cause of the hospital obituary.

The mean hospital stay and the occurrence of death in the groups with $\operatorname{PrD}$, and without delirium on admission, as well as the groups with $\mathrm{InD}$ and without delirium, were compared. To study the duration of hospital stay, patients who died were excluded from the analysis because we believe the relationship between hospital stay and mortality in these cases may be inverted, if the more seriously ill patients died more rapidly.

The respective research project for this study was approved by the Research Ethics Committee of the São Lucas Hospital at the Pontifical Catholic University of Rio Grande do Sul State. All regulations concerning patient privacy and the handling of the manuscripts were fully respected. In view of the fact that this research was conducted entirely from the patients' hospital files, informed consent forms were deemed unnecessary.

To compare the frequencies of $\operatorname{PrD}$ and $\mathrm{InD}$ according to demographic and clinical variations, and mortality, the basic chi-squared test was used, while for the age groups the chi-squared trend test was applied. In the analysis of mortality, Fisher's exact test was used whenever an expected value of less than five was found. The comparison of mean hospitalization times of the groups with and without delirium, either prevalent or incident, was performed using Student's $t$ test. The significance level was assumed as $5 \%$. The data was analyzed with the SPSS software package version 11.5.

\section{Results}

Table 1 lists the demographic and clinical data of the 
261 patients analyzed in this study. Patient ages ranged from 60 to 104 years, having a mean of 79.9 years $(S D=8.4)$. The predominant characteristics were female gender $(58.4 \%)$, more than 80 years old (54.8\%), public health system patients (53.3\%), and suffering from acute disease (72.5\%). The most frequent reasons for hospitalization were elective clinical indication (22.2\%) followed by respiratory infections (12.3\%). The mean length of hospital stay was 13.2 days ( $\mathrm{SD}=11.2$ ), and 32 patients $(12.3 \%)$ evolved to hospital death.

The total incidence of delirium was $42.5 \%$, with $\operatorname{PrD}$ occurring in $31.4 \%$, and $\mathrm{InD}$ in $16.2 \%$. The incidence of PrD differed according to age with a tendency to rise with increasing age and to be higher in the group hospitalized in the private patients' beds. $(36.9 \%$ v. $26.6 \%, \mathrm{p}=0.075)$. The proportion of $\operatorname{PrD}$ in patients hospitalized for acute conditions was higher $(42.6 \%$ v. $1.4 \%, \mathrm{p}<0.001)$. With regard to the reason for hospitalization, $\operatorname{PrD}$ was more frequent in cases of urinary infection (73.9\%), collateral medication effect $(71.4 \%)$, acute abdominal surgery $(57.1 \%)$ and respiratory infection $(53.6 \%)$. No statistically significant difference in InD frequency was found that could be traced to the demographic and/or clinical characteristics.

The duration of hospital stay and mortality rate was the same in patients with and without $\operatorname{PrD}$ (Table 2). In patients with $\mathrm{InD}$, however, the mean length of hospital stay was 9.1 days, and mortality was $48.3 \%$, significantly greater than in the individuals without delirium who presented a mean hospital stay of 1.2 days $(\mathrm{p}=0.002)$ and a mortality rate of $2.7 \%(\mathrm{p}<0.001)$.

\section{Discussion}

Research on delirium is subject to innumerable methodological problems due to the lack of clarity surrounding its physiopathology and the lack of consensus with respect to the criteria for diagnosis. Notwithstanding these issues, the

Table 1. Time of delirium onset, demographic and clinical characteristics.

\begin{tabular}{|c|c|c|c|c|c|c|c|}
\hline & \multirow[b]{2}{*}{$\mathbf{N}(\%)$} & \multicolumn{3}{|c|}{ Prevalent delirium ${ }^{*}$} & \multicolumn{3}{|c|}{ Incident delirium } \\
\hline & & $\mathbf{N}$ & $\%$ & $\mathbf{p}^{\dagger}$ & $\mathbf{N}$ & $\%$ & $\mathbf{p}$ \\
\hline Sex & & & & 0.202 & & & 0.681 \\
\hline Male & $106(40.6)$ & 38 & 35.8 & & 12 & 17.6 & \\
\hline Female & $155(59.4)$ & 44 & 28.4 & & 17 & 15.3 & \\
\hline Age group & & & & 0.020 & & & 0.369 \\
\hline $60-69$ & $28(10.7)$ & 4 & 14.3 & & 4 & 16.7 & \\
\hline $70-79$ & $90(34.5)$ & 26 & 28.9 & & 7 & 10.9 & \\
\hline 80 or older & $143(54.8)$ & 52 & 36.4 & & 18 & 19.8 & \\
\hline Health Plan & & & & 0.075 & & & 0.532 \\
\hline Public & $139(53.3)$ & 37 & 26.6 & & 15 & 14.7 & \\
\hline Private & $122(46.7)$ & 45 & 36.9 & & 14 & 18.2 & \\
\hline Type of hospitalization & & & & $<0.001$ & & & 0.577 \\
\hline Acute & $190(72.8)$ & 81 & 42.6 & & 19 & 17.4 & \\
\hline Elective & $71(27.2)$ & 1 & 1.4 & & 10 & 14.3 & \\
\hline Reason for hospitalization & & & & $<0.001$ & & & 0.318 \\
\hline Elective clinical ${ }^{\ddagger}$ & $58(22.2)$ & 1 & 1.7 & & 7 & 12.3 & \\
\hline Respiratory infection & $56(21.5)$ & 30 & 53.6 & & 5 & 19.2 & \\
\hline Urinary infection & $23(8.8)$ & 17 & 73.9 & & 3 & 50.0 & \\
\hline Other infection & $19(7.3)$ & 3 & 15.8 & & 4 & 25.0 & \\
\hline Acute renal insufficiency & $15(5.7)$ & 7 & 46.7 & & 1 & 12.5 & \\
\hline Heart disease $\mathrm{e}^{\S}$ & $13(5.0)$ & 2 & 15.4 & & 0 & 0.0 & \\
\hline Elective surgery & $13(5.0)$ & 0 & 0.0 & & 3 & 23.1 & \\
\hline Collateral medication effect & $7(2.7)$ & 5 & 71.4 & & 0 & 0.0 & \\
\hline Acute abdominal & $7(2.7)$ & 4 & 57.1 & & 0 & 0.0 & \\
\hline Other & $50(19.2)$ & 13 & 26.0 & & 6 & 16.2 & \\
\hline Total & $261(100)$ & 82 & 31.4 & -- & 29 & 16.2 & -- \\
\hline
\end{tabular}

*Prevalent delirium: proportion of delirium diagnosed within the first 24 hours of Hospital admission. Incident delirium: proportion of delirium diagnosed during hospital stay in patients who were delirium-free on arrival; "Values obtained from the $\chi^{2}$ test. For the variable age, the $\chi^{2}$ trend test was used; ${ }^{\ddagger}$ Includes: non-surgical diagnostic investigation,

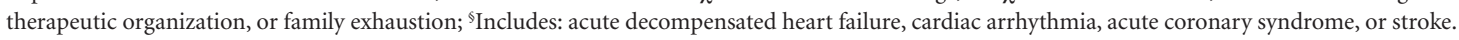


Table 2. Time of delirium onset, duration of hospital stay and mortality.

\begin{tabular}{lccc}
\hline & \multicolumn{2}{c}{ Prevalent delirium } & \\
\cline { 2 - 3 } & Yes & No & p \\
\hline $\mathrm{N}$ & 82 & 179 & \\
Duration of hospital stay in days, of elderly & & & $0.602^{*}$ \\
patients who were discharged (mean \pm SD) & $12.3 \pm 9.9$ & $13.1 \pm 11.0$ & \\
Mortality N (\%) & $14(17.1)$ & $18(10.1)$ & $0.109^{\dagger}$ \\
\hline & Incident delirium & \\
\cline { 2 - 3 } & Yes & No & p \\
\hline N & 29 & 150 & \\
Duration of hospital stay in days, of elderly & & & $0.002^{\star}$ \\
patients who were discharged (mean \pm SD) & $21.3 \pm 11.0$ & $12.2 \pm 10.7$ & \\
Mortality N (\%) & $14(48.3)$ & $4(2.7)$ & $<0.001^{*}$ \\
\hline
\end{tabular}

${ }^{*}$ test; ${ }^{\dagger}$ Chi-squared test; ${ }^{*}$ Fisher's exact test.

results of the present study as regards the frequency of the incidence of delirium, and the association of $\operatorname{PrD}$ with older age, acute care hospitalization, and the reasons for hospitalization all agree with the data in the literature. ${ }^{7,15,17,22,28}$ The greater prevalence of delirium found in patients with urinary infections and collateral medication effects can be explained by the fact that the signs and symptoms involved with these conditions are less apparent amongst the elderly, delaying diagnosis and increasing the chances of developing acute confusion states before treatment is initiated.

We found no statistically significant association between $\operatorname{PrD}$ and prognosis in spite of the greater mortality in the group that presented delirium on admission. It is possible that our sample was too small to demonstrate any difference. Also, we excluded those patients who had been spent more than 24 hours outside the geriatric ward where these patients would generally be in a more serious condition, and would probably have presented with delirium on admission and have a poorer diagnosis. delirium that initiated during hospitalization, however, was strongly associated with both the duration of hospital stay and mortality. This difference between $\operatorname{PrD}$ and $\mathrm{InD}$ was first described by Mc Cusker et al., who found longer periods of hospitalization in patients with $\mathrm{InD}$ and no association of $\mathrm{PrD}$ with prognosis. ${ }^{24}$

The difference found in the prognostic values of $\operatorname{PrD}$ and $\mathrm{InD}$ suggests that $\mathrm{PrD}$ is not necessarily an indicator of serious illness, and may be more closely related to previous vulnerable states (for instance: advanced age, cognitive impairment, institutionalization, fragility) which facilitate the onset of a confusional state. This neurological fragility likely influences the outcome but to a lesser extent than the degree of severity of acute disease. On the other hand, patients that developed $\mathrm{InD}$, but were admitted to the hospital problem-free generally demonstrated less vulner- ability. The occurrence of $\mathrm{InD}$ in these patients would indicate, therefore, negative evolution of the conditions that led to hospitalization in the first place, or occurrence of a hospital-acquired complication.

Clinical, epidemiological and basic scientific evidence supports the hypothesis that delirium is merely an indicator of prognosis and is not itself a cause of a poor prognosis. ${ }^{11,18,29}$ The significance of delirium may lie in its ability to reveal a deleterious interaction between the individual and the aggressor factor. In some cases, increased individual vulnerability could lead to a greater occurrence of PrD, less relevant for the prognosis. In other cases, because of more aggressive disease, which is generally the cause of the appearance of $\mathrm{InD}$, the prognosis is worse. Considering the greater prevalence of $\operatorname{PrD}(31.4 \%$ v. $16.2 \%)$, it seems that increased individual vulnerability is more frequent in elderly patients with acute disease. This is clearly evident in cases of delirium due to benign problems, such as fecal impaction or mild dehydration which, in the majority of cases, would not justify hospitalization, much less lead to a prolonged hospital stay or a greater rate of mortality.

The mortality among the delirium-free group was much lower in comparison to patients who presented delirium $(2.7 \%$ v. $25 \%)$ at some point, and this result is in line with findings of other studies. ${ }^{11,17}$ Therefore, the absence of delirium appears to indicate some degree of prognostic protection rather than the opposite. This finding may help to reach decisions in complicated situations where there is doubt over indicating invasive interventions in hospitalized elderly patients. The absence of acute confusional state in the patient's file would thus indicate a good prognosis, or less individual vulnerability, and consequently, lower risk of unfavorable evolution.

First recognizing that amongst elderly hospitalized in 
geriatric wards, $\operatorname{PrD}$ is more related to an increased state of individual vulnerability (which has little effect on the prognosis), and that secondly, the occurrence of $\mathrm{InD}$ is most likely due to a serious situation (indicating evolution to worsened state), can help to clarify the role played by delirium as an indicator in prognosis - although this matter remains controversial. We believe, however, that it is fundamental to differentiate the time of delirium onset. In addition, the absence of delirium seems to be an important protective factor that could assist decision making regarding diagnostic and therapeutic procedures in hospitalized elderly patients. However, this hypothesis requires further elucidation.

Acknowledgments - In closing, we would like to thank Professor Dr. José Luiz da Costa Vieira for his support during the conducting of this study. The authors declare that they have no potential conflicts of interest pertaining to the present study.

\section{References}

1. Projeções e estimativas demográficas (2001-2006). Instituto Brasileiro de Geografia e Estatística (IBGE) http://www.ibge. gov.br Access date April 2009.

2. Castro M. A utilização das internações hospitalares no Brasil: fatores associados, grandes usuários, reinternações e efeito da oferta de serviços sobre o uso. Rio de Janeiro: Escola Nacional de Saúde Pública da Fundação Osvaldo Cruz; 2004:101.

3. Meneghell S, Armani T, Rosa R et al. Internações hospitalares no Rio Grande do Sul. Informe Epidemiológico do SUS 1997;6:49-59.

4. Loyola Filho A, Matos D, Giatti L, et al. Causas de internações hospitalares entre idosos brasileiros no âmbito do Sistema Único de Saúde. Epidemiologia e Serviços de Saúde 2004;13:229-238.

5. Lipowski ZJ. Delirium (acute confusional states). JAMA 1987; 258:1789-1792.

6. Fabbri R. Delirium. In: Freitas E, Py L, Cançado F, Doll J, Gorzoni M, editors. Tratado de Geriatria e Gerontologia, 2nd. Rio de Janeiro: Guanabara Koogan; 2006:325-332.

7. Agostini J, Inouye S. Delirium. In: Hazzard W, Blass J, Halter J, Ouslander J, Tinetti M, editors. Principles of Geriatric Medicine and Gerontology, $5^{\text {th }}$. New York: McGraw-Hill; 2003: 1503-1515.

8. Gillick MR, Serrell NA, Gillick LS. Adverse consequences of hospitalization in the elderly. Soc Sci Med 1982;16:1033-1038.

9. Inouye SK, Schlesinger MJ, Lydon TJ. Delirium: a symptom of how hospital care is failing older persons and a window to improve quality of hospital care. Am J Med 1999;106:565-573.

10. Inouye SK. Delirium in older persons. N Engl J Med 2006;354: 1157-1165.

11. Francis J, Martin D, Kapoor WN. A prospective study of delirium in hospitalized elderly. JAMA 1990;263:1097-1101.
12. Lawlor PG, Gagnon B, Mancini IL et al. Occurrence, causes, and outcome of delirium in patients with advanced cancer: a prospective study. Arch Intern Med 2000;160: 786-794.

13. Pisani MA, McNicoll L, Inouye SK. Cognitive impairment in the intensive care unit. Clin Chest Med 2003;24:727-737.

14. Kakuma R, du Fort GG, Arsenault L et al. Delirium in older emergency department patients discharged home: effect on survival. J Am Geriatr Soc 2003;51:443-450.

15. Inouye SK, Bogardus ST, Jr. Charpentier PA et al. A multicomponent intervention to prevent delirium in hospitalized older patients. N Engl J Med 1999;340:669-676.

16. Cole MG, Primeau FJ. Prognosis of delirium in elderly hospital patients. CMAJ 1993;149:41-46.

17. Pompei P, Foreman M, Rudberg MA, et al. Delirium in hospitalized older persons: outcomes and predictors. J Am Geriatr Soc 1994;42:809-815.

18. O'Keeffe S, Lavan J. The prognostic significance of delirium in older hospital patients. J Am Geriatr Soc 1997;45:174-178.

19. Adamis D, Treloar A, Darwiche FZ, et al. Associations of delirium with in-hospital and in 6-months mortality in elderly medical inpatients. Age Ageing 2007;36:644-649.

20. Siddiqi N, House AO, Holmes JD. Occurrence and outcome of delirium in medical in-patients: a systematic literature review. Age Ageing 2006;35:350-364.

21. Adamis D, Treloar A, Martin FC, et al. Recovery and outcome of delirium in elderly medical inpatients. Arch Gerontol Geriatr 2006;43:289-298.

22. Formiga F, Marcos E, Sole A, et al. Acute confusional syndrome in elderly patients hospitalized due to medical condition. Rev Clin Esp 2005;205:484-488.

23. Bellelli G, Frisoni GB, Turco R, et al. Delirium superimposed on dementia predicts 12 -month survival in elderly patients discharged from a postacute rehabilitation facility. J Gerontol A Biol Sci Med Sci 2007;62:1306-1309.

24. McCusker J, Cole MG, Dendukuri N, et al. Does delirium increase hospital stay? J Am Geriatr Soc 2003;51:1539-1546.

25. Inouye SK. The dilemma of delirium: clinical and research controversies regarding diagnosis and evaluation of delirium in hospitalized elderly medical patients. Am J Med 1994;97: 278-288.

26. Fabbri RM, Moreira MA, Garrido R, et al. Validity and reliability of the Portuguese version of the Confusion Assessment Method (CAM) for the detection of delirium in the elderly. Arq Neuropsiquiatr 2001;59:175-179.

27. Inouye SK, van Dyck CH, Alessi CA, et al. Clarifying confusion: the confusion assessment method. A new method for detection of delirium. Ann Intern Med 1990;113:941-948.

28. Edlund A, Lundstrom M, Karlsson S, et al. Delirium in older patients admitted to general internal medicine. J Geriatr Psychiatry Neurol 2006;19:83-90.

29. Bellelli G, Morghen S, Turco R, et al. Delirium in older people: an epiphenomenon of incipient death or a separate biological process? Age Ageing 2008;37:353-354; author reply 355. 